\title{
Социальные сети как канал коммуникации с властью (на примере протестных движений Ярославской области)
}

\author{
А.В. Соколов, Д.Е. Платников \\ Ярославский государственный университет им. П.Г. Демидова \\ alex8119@mail.ru, denipa-1@rambler.ru
}

\section{Аннотация}

Статья посвящена анализу возможностей влияния общественных кампаний в социальных сетях на процесс принятия решений органами власти. Авторами рассматриваются основные преимущества Интернета, информационнокоммуникативных технологий и социальных сетей. Указывается, что они предоставляют возможности получить доступ к альтернативным источникам информации, создать условия для открытых дискуссий, вовлечь молодежь в общественно-политическую активность, обеспечить обратную связь с деятельностью органов власти, координировать коллективные действия, выстраивать неиерархическую организационную структуру. Отмечается, что социальные сети позволяют формировать альтернативное информационное пространство, позволяющее преодолевать цензуру. В статье рассматривается пример влияния кампании в социальных сетях на решения и действия органов власти в Ярославской области: против складирования московского мусора на территории региона. В ходе анализа была выявлена интенсивность освещения проблемы в социальных сетях, использованные инструменты. Авторами делается вывод о том, что Интернет становится неотъемлемой частью жизни общества, увеличивая возможности влияния граждан на процесс принятия решений органами власти.

Ключевые слова: Интернет, социальные сети, протест, власть, коммуникация, коллективные действия

Библиографическая ссылка: Соколов А.В., Платников Д.Е. Социальные сети как канал коммуникации с властью (на примере протестных движений Ярославской области) // Государство и граждане в электронной среде. Выпуск 3 (Труды XXII Международной объединенной научной конференции «Интернет и современное общество», IMS-2019, Санкт-Петербург, 19 - 22 июня 2019 г. Сборник научных трудов). - СПб: Университет ИТМО, 2019. С. 132 - 143. DOI: 10.17586/2541-979X2019-3-132-143

\section{1. Преимущества Интернета и социальных сетей в процессе организации коллективных действий и влияния на решения власти}

Гражданская активность является как следствием, так и причиной трансформации социально-экономической и общественно-политической ситуации в стране. Граждане, не находя отклика от органов власти, должностных лиц, вынуждены самоорганизовываться для привлечения внимания власти, решения существующих дисбалансов. Данная активность граждан может приобретать различные формы, как конструктивного диалогового взаимодействия с официальными институтами, так и различных форм конфликтного действия.

Значительные проблемы и дисбалансы в обществе вызывают не отдельные случаи гражданской активности, а формирование и развитие массовых общественных движений. 
Теория мобилизации ресурсов рассматривает общественные движения как коллективные субъекты, которые стремятся оптимизировать аккумулирование и использование материальных и не материальных ресурсов для достижения целей коллективного действия [7].

Бурное развитие технологий также предопределило существенные трансформации гражданской активности и общественных движений, механизмов и инструментов их организации. Ключевое значение здесь сыграло развитие сети Интернет, а также широкое распространение средств коммуникации (в том числе, их удешевление и массовое распространение). В следствие активного развития ИКТ Интернет эволюционировал из средства коммуникации и передачи информации в новую среду жизнедеятельности.

Этому способствовало активное формирование и развитие средств и каналов коммуникации, ускорявших и облегчавших передачу информации и мнений в процессе самоорганизации и коллективных действий, вовлечение новых сторонников и активистов.

Целый ряд исследований направлен на выявление тех преимуществ, которые предоставляет Интернет. О.Г. Филатова среди них отмечает: мультимедийность, персонализацию, интерактивность, отсутствие посредников [23].

Обобщая различные исследования, можно отметить, что Интернет и ИКТ предоставляют следующие возможности:

- получать доступ к альтернативным источникам информации [10];

- облегчать ведение дискуссий различных заинтересованных субъектов [3];

- вовлекать новых участников (в том числе молодежь) [14];

- выстроить систему обратной связи с органами управления и официальными структурами [6].

К. Уэлльс в рамках собственных исследований выявил следующие преимущества использования Интернета в гражданской активности:

- облегчение координации действий активистов;

- формирование новых организационных структур (базирующихся на равноправии, горизонтальной коммуникации);

- создание новых условий и возможностей для мобилизации активистов.

Важным преимуществом Интернета и его каналов коммуникации заключается в предоставлении возможности передачи информации, опубличивании новостей и различных позиций. Особенно важным данное преимущество является в процессе различных форм конфликтных и протестных коллективных действий.

В результате, как отмечает С.В. Володенков, Интернет и ИКТ становятся новым фактором формирования повестки дня и общественного мнения, влияния на политический процесс [20]. Особое значение, как подчеркивает исследователь, указанные технологии приобретают в конфликтных и протестных акциях.

Особую значимость Интернета в процессе мобилизации новых сторонников в гражданской активности отмечал К. Ширки [15]. Однако вовлечение значительного количества участников усложняет процесс координации их действий, согласование общих требований. 3. Тафочи указывает, что возможности ускоренной мобилизации сторонников и активистов лишают возможности получения организаторами значительного опыта организационной, координационной и мобилизационной деятельности [17]. Другим следствием являются упущенные возможности выявления и рекрутирования новых лидеров, формирования у них навыков успешной активности в рамках коллективных действий).

В тоже время, интенсивная коммуникация в сети Интернет в сообществе активистов позволяет выявлять новых лидеров, формировать им социальный капитал, массовую поддержку и доверие. В результате они обладают большим потенциалом влияния на общественное мнение, а также возможностями направлять деятельность вовлеченных активистов [19]. Данные лидеры функционируют на принципах сети, независимы от официальных структур, обладают собственными ресурсами. Это позволяет им действовать 
независимо, стремясь реализовать свои цели в коллективном действии. Это создает угрозу сформированной системе власти и ее лидерам [22]. Важным следствием этого также является децентрализация процесса передачи информации и коммуникации. В результате разрушается традиционная асимметрия и иерархия.

Важной особенностью Интернет-коммуникации является возможность выстраивать таргетированое взаимодействие. Это не только облегчает, ускоряет коммуникацию, но также облегчает вовлечение новых лояльных активистов. Сетевой принцип их функционирования позволяет менять традиционные «правила игры» вертикального взаимодействия и коммуникаций, обходить цензурирование информационного пространства [16]. Тем самым создаются определённые локусы новой активности, нового потенциала влияния на социально-политическое и информационное пространство.

Таргетирование коммуникации, общность цели, инициативность, идентичность создают общности, обладающие уникальными характеристиками с общим видением социальной реальности. При определенных условиях данные сообщества становятся замкнутыми на собственной картине мире, снижая восприимчивость к «чужим» точкам зрения, интересам. Члены данных сообществ черпают информацию и аргументы из информационного потока, в рамках которого они находятся.

Постоянная тематическая коммуникация позволяет формировать внутригрупповую идентичность, которая также повышает эффективность коммуникации и коллективного действия челнов самоорганизующихся групп.

М. Кастельс выдвинул гипотезу о том, что «арабская весна» стала следствием сетевого взаимодействия, основанного на социальной неудовлетворённости, создавая надежду на изменение социального пространства посредством коллективного действия на основе Интернет-коммуникации [4]. При этом П. Гербаудо отмечал, что успешность протестов в арабском мире обеспечивалась целенаправленностью коммуникаций и сочетанием онлайн и офлайн активности [9].

Ключевым каналом коммуникации в Интернете стали социальные сети, как самый доступный и многофункциональный инструмент, позволяющий реализовать потенциал Интернета.

При этом не существует единого мнения относительно роли социальных сетей. В рамках первого подхода исследователи отказывают социальным сетям в статусе средства массовой информации, интерпретируя их только как канал передачи информации между отдельными индивидами [21]. Другие признают значимость социальных сетей, указывают, что каждый пользователь может выступить создателем, интерпретатором и транслятором информации [18]. В нашей работы социальные сети понимаются именно в рамках второго подхода.

Использование социальных сетей может способствовать мобилизации новых активистов в общественные движения [11], тем самым укрепляя их [8], вследствие оперативного получения информации о движении. Социальные сети предоставляют широкий спектр возможностей для коммуникации и взаимодействия активистам. Среди них можно выделить:

- обеспечение чувства вовлеченности в деятельность сообщества посредством нахождения в едином информационном пространстве [5];

- возможность выражение собственного мнения, результатом чего может быть вовлечение новых активистов [12];

- преодолевать широкий спектр барьеров (географических, социальных и т.д.) [2];

- формировать групповую идентичность [1].

Таким образом, Интернет создает новые возможности для включения граждан в процесс коллективных действий по устранению сформировавшихся дисбалансов (быстрая мобилизация, эффект вовлеченности, таргетированность коммуникации). При этом, ИКТ формируют дополнительные условия для аккумулирования социального капитала, выявления новых лидеров. Тем самым формируются комфортные для активистов условия 
и формы деятельности, повышается устойчивость коллективного действия, снижаются потребности в ресурсах на организацию коллективного действия.

\section{2. Методика исследования}

Активизация гражданского участия на основе использования ИКТ наблюдается не только на государственном, но и на региональном и местном уровнях. Это стало возможно благодаря объединению пользователей социальных сетей вокруг определенной территории. Так, нередко можно увидеть неофициальные страницы жителей одного города, поселка или региона. В подобных сообществах процесс распространения локальной информации намного быстрее, а отклик на полученную информацию наиболее точный. Так, если проблему заметил один житель небольшого города и рассказал об этом в социальных сетях, то другие жители этого города наверняка увидят это сообщение, поделятся им, отреагируют. Постепенно вокруг проблемы возникает группа заинтересованных в ее решении, формируются связи между людьми, выдвигаются лидеры общественного мнения. Если действующая власть не реагирует на подобные процессы, то они могут перерасти в открытое противостояние населения и властных структур.

С целью исследования вышеизложенных проблем было проведено исследования возможностей влияния общественно-политических кампаний в Ярославской области, организованных в социальных сетях, на процесс принятия решений органами власти, их позицию по проблеме, ставшей отправной точкой коллективных действий граждан. Авторами был проведен анализ кампании, организованной в Ярославской области в 2018 году, против складирования московского мусора на территории региона.

В качестве теоретико-методологической основы исследования выступает теория коллективного действия, объясняющая, при каких условиях люди способствуют обеспечению коллективного или общественного блага. При этом протест рассматривается через призму теории коллективного действия, как проявление недовольства и обид, позволяющее снять накопившееся напряжение из-за социальных или психологических деформаций.

Прикладными инструментами анализа протестного движения стали методика контент анализа сообщений региональных средств массовой информации с использованием информационно-аналитической системы «Медиалогия» и сервиса socstat.ru и включенное наблюдение за массовыми публичными проявлениями протестной активности.

Объектами контент анализа стали 48 региональных и центральных информационных Интернет-агентств, 24 районных печатных изданий, 20 областных, 30 центральных печатных изданий; 4 региональные радиокомпании; 17 телекомпаний; тематические сообщества в региональных сегментах социальных Интернет-сетей «Facebook», «ВКонтакте», «Одноклассники», региональном интернет-форуме «Ярпортал» (468 групп, 219 страниц пользователей), а также региональные чаты и каналы в мессенджере Telegram (9). В выборку включались сообщения, в которых употреблялось словосочетание «московский мусор». Период наблюдения - 19 марта - 31 июля 2018 г.

\section{3. Коллективные действия против размещения твердых бытовых отходов из Москвы и Подмосковья в Ярославской области}

В начале апреля 2018 года Ярославскую область всколыхнули сообщения, появившиеся в средствах массовой информации - в регионе планируется размещение твердых бытовых отходов (далее по тексту - ТБО) из Москвы и Подмосковья. Власти объясняли это тем, что необходимо помочь соседнему региону в предотвращении экологической катастрофы, спровоцировать которую могли переполненные мусорные полигоны. 
Невнятная реакция на первые сообщения представителей региональной власти и губернатора региона, отсутствие достоверной информации о планах взаимодействия с соседним регионом в данном вопросе только усугубили ситуацию и привели к первым акциям протеста. Постепенно протестное движение ярославцев против ввоза ТБО из Москвы и Московской области приобрело системный и организованный характер (получившего в регионе название «Против московского мусора»). Произошли серьезные изменения в общественном сознании в отношении к органам власти ее руководителям. Свидетельством тому стало появление первых призывов уйти в отставку, адресованные действующему губернатору региона, победившему на выборах лишь в сентябре 2017 г. с внушительным результатом именно в ходе антимусорных акций.

Сформированное экоактивистами и неравнодушными жителями Ярославля протестное движение «Против московского мусора» практически сразу обрело свою коллективную идентичность. А. Мелуччи определяет ее как «интерактивная и обобщенная категория, создаваемая несколькими индивидуумами (или на более сложном уровне - их группой) и связанная с представлениями о действиях, а также возможностях и ограничениях относительно данных действий» [13, с. 44]. Формирование коллективной идентичности важная предпосылка для формирования и трансляции общего понимания происходящих событий.

Основой для формирования коллективной идентичности участников и сторонников протестов «Против московского мусора» стала защита «родной земли» от «варягов». Губернатор Д.Ю. Миронов - выходец из силовых структур, неярославец, был назначен исполнять обязанности главы региона в июле 2016 года и первые полтора года вся его деятельность была направлена на то, чтобы стать «своим» в регионе. Звучали заявления о привлечении в область небывалого количества инвестиций, обещания строительства новых социальных объектов, были разработаны планы решения застарелых социальных проблем (дорожной, ЖКХ, здравоохранения). В результате жители региона оказали Д.Ю. Миронову поддержку в ходе прошедших в сентябре 2017 г. губернаторских выборов $(79,32 \%)$.

10 апреля 2018 г. Д.Ю. Миронов объявил о том, что ярославский полигон «Скоково» будет принимать московский мусор. Заявление прозвучало неожиданно, ведь до этого власти уверяли обеспокоенную общественность, что ничего не происходит, и проблемы нет. Все надежды ярославцев на защиту сильного губернатора оказались разбиты и в массовом сознании актуализировалась тема «варягов» - так протестующие окрестили команду областного правительства, составленную выходцами из Подмосковья. Произошло четкое разделение на «свой-чужой» по признаку происхождения.

Появились сетевые мемы, подчеркивающие оскорбленность ярославцев не только самим фактом ввоза мусора в регион, сколько фактом его столичного происхождения («Мой город - не помойка», «Москоково», «Московскому мусору дороги в Ярославль нет», «\#СобянинЗабери» и т.д.).

В данном контексте обратим внимание, что большую роль в формировании протестной идентичности сыграли технологии, облегчившие коммуникации в большой группе протестующих, что позволило сформировать устойчивые связи и сопричастность внутри сообщества. Так, по состоянию на 15 июля 2018 крупнейший паблик антимусорных активистов региона в мессенджере Telegram насчитывал 651 пользователь, что по меркам Ярославской области составляет внушительную цифру, и позволяло ему являться вторым на тот момент по числу участников среди подобных региональных сообществ. Были созданы группы в основных социальных сетях, которые также насчитывали несколько тысяч участников, сотни сообщений в день. Так, охват региональной Интернет-аудитории постами крупнейшего регионального антимусорного паблика ВКонтакте к середине мая 2018 г. превышал 45 тыс. человек (Рисунки 1-3).

Таким образом, идентичность позволила сформировать активную протестную группу «Против московского мусора», мобилизовывать сторонников для участия в протестных 
акциях. При этом, политизация коллективной идентичности борцов с московским мусором произошла достаточно быстро с начала протестного движения. Недовольство ввозом отходов практически с первого дня трансформировалось в требования к власти прекратить его. Политизация привела к радикализации действий протестующих, из-за отказа региональных властей прекратить ввоз мусора из соседнего региона - уже 18 апреля 2018 года на митинге прозвучало требование «Миронова в отставку!».

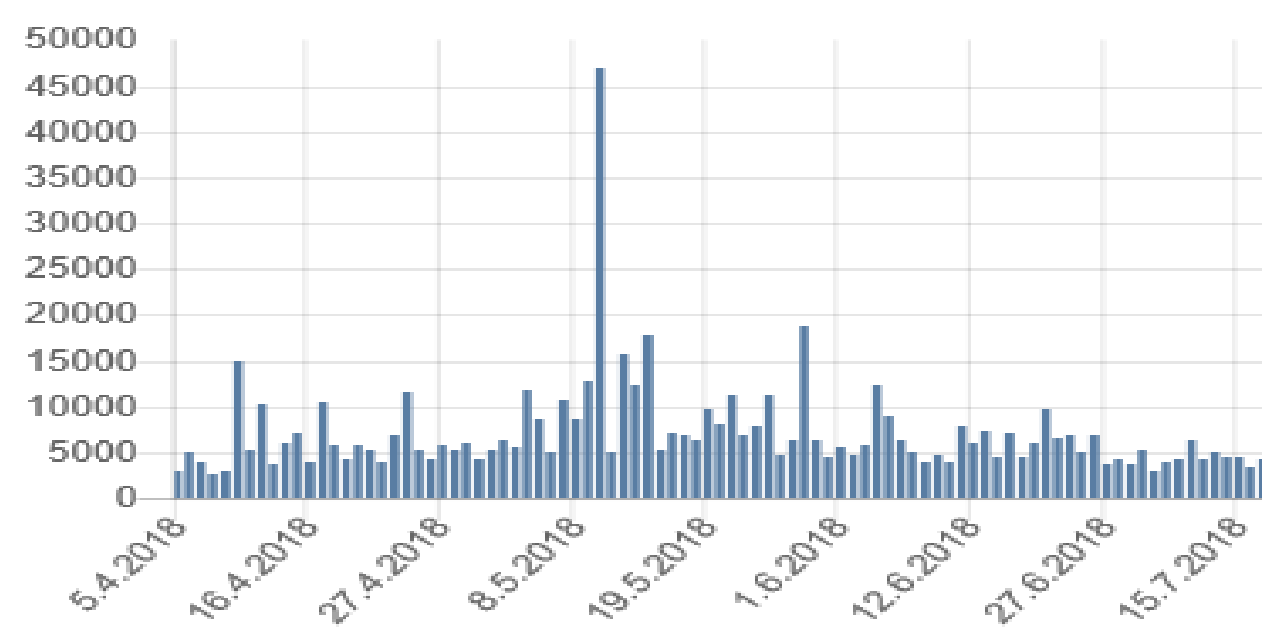

Рис. 1. Динамика охвата постов от имени сообщества «Московский мусор в Ярославской области» (по результатам замеров, произведенных инструментарием сервиса socstat.ru)

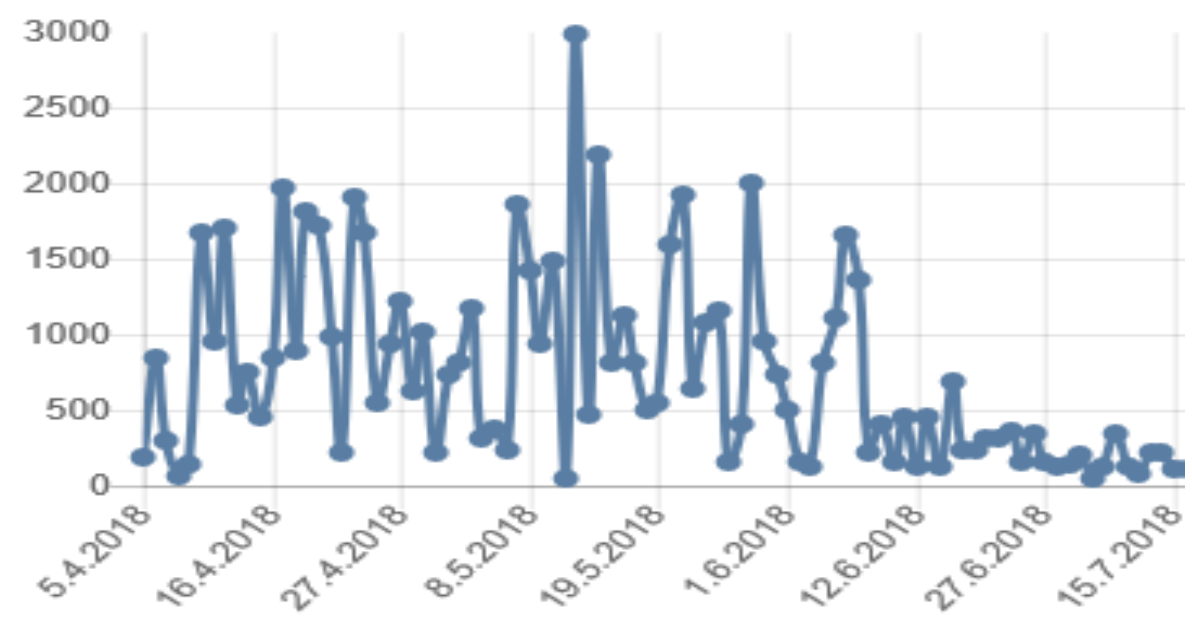

Рис. 2. Динамика реакций на контент сообщества «Московский мусор в Ярославской области» (лайки+репосты+комментарии)

(По результатам замеров, произведенных инструментарием сервиса socstat.ru)

Любопытно, при этом сравнить активность традиционных масс-медиа и пользователей социальных сетей в обсуждении проблемы ввоза отходов. Результаты исследования показали, что печатные, теле- и радио СМИ, а также интернет-информагентства не 
обходили тему вниманием, но в них доминировала точка зрения региональных властей на развитие ситуации (рисунок 3). «ИА Regnum», Сайт ЯРО КПРФ, «Яркуб», «Ярновости», «Вид сбоку. Ярославль» 76.ру, детально и пристально следили за ситуацией; значительная часть информации (в том числе - фото- и видеорепортажи) подавалась со ссылкой на соцсети. Журналисты не только анонсировали протестные акции, но и со ссылкой на активистов, «Комитет народной обороны Ярославля» публиковали инструкции по практическим действиям (правила поведения на митинге, схемы обращения в надзорные органы и органы власти по проблеме и др.) и варианты решения проблем утилизации мусора. СМИ регулярно информировали о ходе сбора подписей под петицией «Законодательно запретите ввоз московского мусора в Ярославскую область» и петицией с требованием досрочно прекратить полномочия Д. Миронова. Значительная часть оппозиционных СМИ ответственность за происходящее возложила на губернатора Д. Миронова. Один из тезисов - Д. Миронов своей позицией по «мусорному вопросу» подставил под удар не только экологическую безопасность, но политическую ситуацию в регионе. Основными ньюсмейкерами стали политики (депутат Облдумы, лидер ЯРО КПРФ А. Воробьев, активист ярославского штаба Навального А. Смирнов, активист, лидер ЯРО «Яблоко» О. Виноградов, А. Ватлин (ЛДПР), депутаты (депутат муниципалитета Е. Овод, депутат MC Ярославского MP В. Пухов), экспертыпрофессионалы (бывший эколог «Скоково» А. Большаков, Л. Байкова и Е. Богданова), юристы (председатель коллегии адвокатов «Академия правовой защиты» Г. Старостина).

Начиная с июня 2018 года тема ввоза мусора в СМИ постепенно сходит на нет, заменяясь в информационном пространстве проектом «Новой экологической политики», которую власть предложила в качестве альтернативной темы для обсуждения экологически заряженной общественности, канализировав тем самым массовый уличный протест в конструктивное русло.

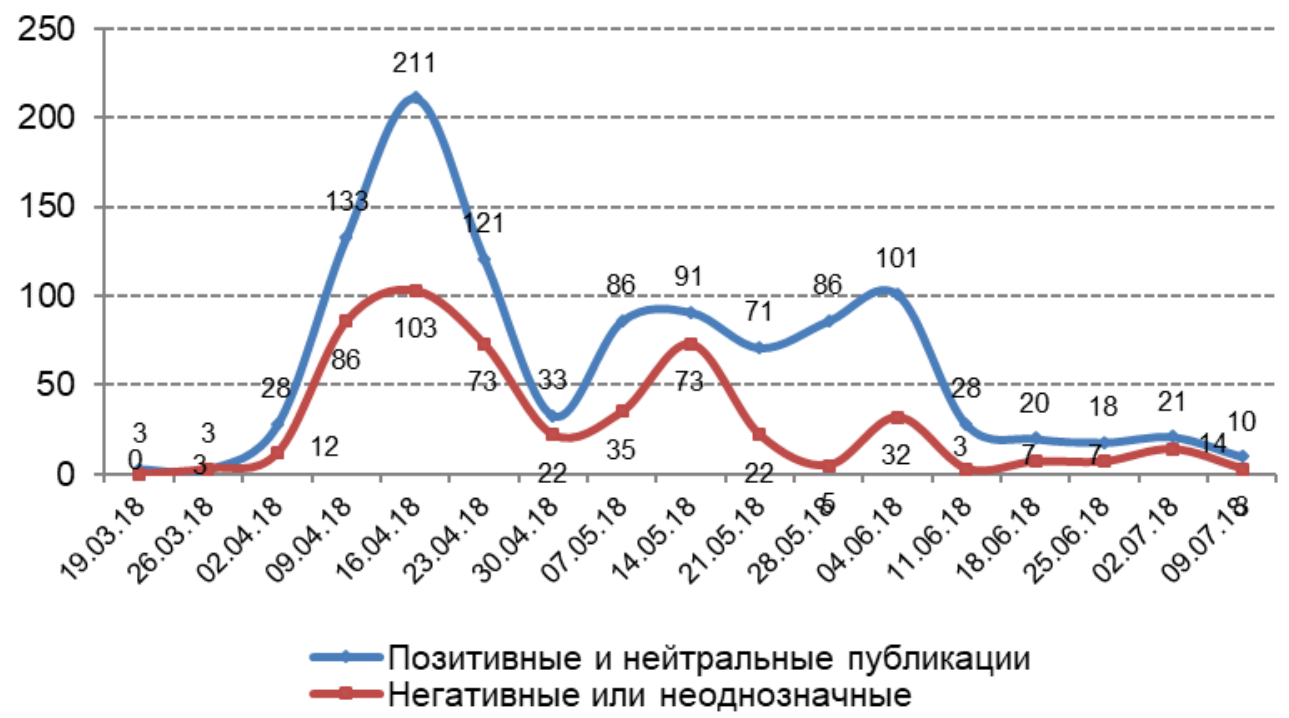

Рис. 3. Обсуждение проблемы ввоза московского мусора в СМИ (количество упоминаний «мусор» в контексте проблемы ввоза отходов в ЯО в сообщениях региональных теле- и радиокомпаний, печатных СМИ и информационных агентств) (По результатам замеров, произведенных с использованием информационно-аналитической системы «Медиалогия»)

В то же время, в социальных сетях пользователи чаще размещали посты, содержащие негативные оценочные суждения относительно развития ситуации. 


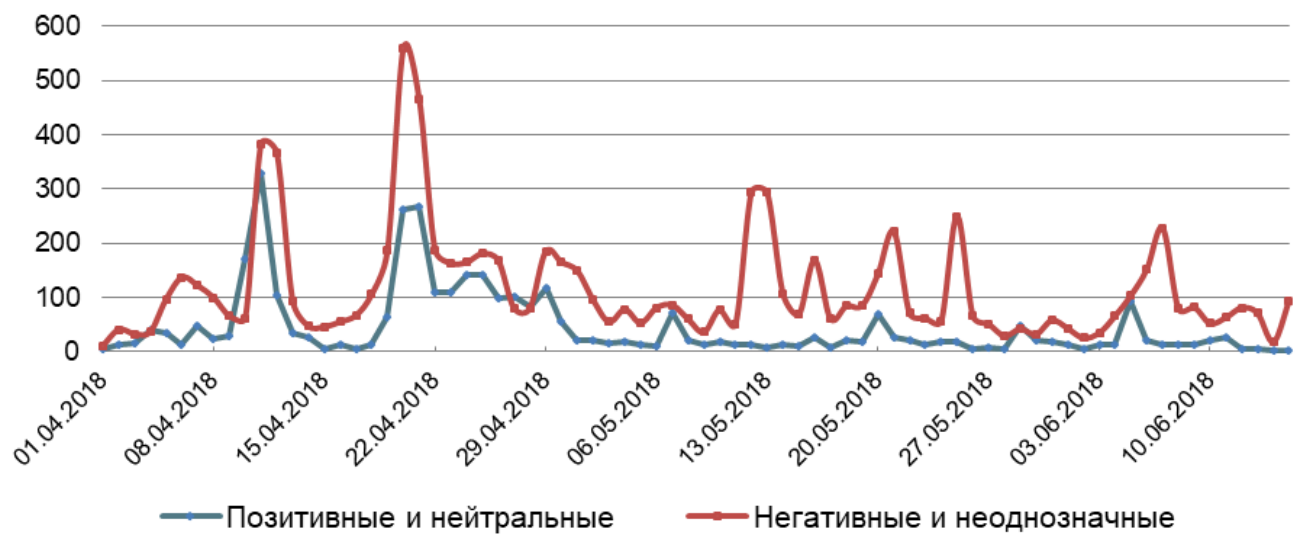

Рис. 4. Обсуждение проблемы ввоза московского мусора в социальных сетях (количество упоминаний «мусор» в контексте проблемы ввоза отходов в ЯО в сообщениях пользователей региона ВКонтакте, Facebook, Instagram, «Одноклассники») (По результатам замеров, произведенных с использованием информационно-аналитической системы «Медиалогия»)

Пользователи социальных сетей активно готовились к акциям протеста, делились фотографиями мусоровозов с регистрационными знаками московского региона, обсуждали предложения властей по сложившейся ситуации.

Любопытным представляется и анализ оффлайн активности движения «Против московского мусора». Так, благодаря мощной сетевой мобилизации, наличию ярко выраженной коллективной идентичности первую публичную акцию протеста удалось провести уже 5 апреля (напомним, первые упоминания о возможности размещения ТБО из Москвы и Подмосковья появились 19 марта, а активное обсуждение в соцсетях началось 1-2 апреля). Всего за апрель-июль 2018 года в городе и области прошло 70 протестных акций различного масштаба, на которых звучали лозунги «Против московского мусора» (в том или ином виде), в которых приняло участие около 3000 человек.

Однако, мобилизация не носила продолжительного характера и постепенно активность существенно снизилась, в том числе, «благодаря» появлению в общественном дискурсе иных проблем, на которое было отвлечено внимание социально активных граждан (например, старт обсуждений вариантов пенсионной реформы). В тоже время следует отметить, что данная информационная кампания в социальных сетях позволила сформировать негативное отношение жителей региона не только к самой проблеме, но и органам власти. Руководство региона было вынуждено начать активное обсуждение проблемы, и, в конечном итоге в 1 января 2019 года, ввоза московского мусора в регион прекратился.

На данном примере была продемонстрирована еще одна особенность социальных сетей - доступность. Социальные сети дают возможность принять участие в протесте не только политическим деятелям, но и широкой общественности, которая объединяется вокруг лидеров общественного мнения, насущных проблем, недовольства деятельностью органов власти. В отличие от крупных политических или общественных кампаний социальные сети не требуют существенных финансовых затрат, но при должном распределении имеющихся ресурсов способны дать удовлетворительный результат.

\section{4. Выводы}

Социальные сети играют роль вторичного фактора изменения политических процессов и институтов, формируя общественное мнение, на которое впоследствии вынуждены 
реагировать власти. При этом принципиально важным моментом является характер этой реакции - декларативный или реальный.

Внутри сети происходит процесс взаимной коммуникации участников, создающей консолидированное мнение и отношение самоорганизованных активистов по ключевой повестке тем самым содействуя организации коллективных действий.

Таким образом, очевидно, что Интернет становится неотъемлемой частью жизни общества, увеличивая возможности влияния граждан на процесс принятия решений органами власти.

В политической сфере виртуальная сеть изначально была призвана решать задачи информирования о деятельности политических представителей, и лишь значительно позднее - о взаимодействии и коммуникации различных групп. Резонанс и широкое освещение в социальных сетях, транслируется в традиционные СМИ, что исключает возможность органам власти не реагировать на освещаемые события.

Ярославский антимусорный кейс демонстрирует, что информационный вакуум традиционных СМИ был успешно компенсирован активным обсуждением проблемы в социальных сетях. Постепенно он позволил сформироваться значительному сообществу активистов, эффективно координирующих коллективные действия, обменивающихся информацией, вовлекающих новых активистов. Важным следствием данной активности стало формирование движения горожан, выступающих против ввоза московского мусора, и обладающего коллективной идентичностью. Это проявлялось и в постепенной политизации деятельности формирующегося сообщества. Данная активность также позволила оказать существенное влияние на общественное мнение, проявлением чего стала радикализация требований протестующих.

Проведенное исследование позволяет говорить о том, что активистам удалось трансформировать коммуникацию, дискуссию в социальных сетях в офлайн активность (было организовано 70 уличных акций).

Активизация деятельности официальных структур, которая нашла свое отражение и в информационном пространстве, позволила преодолеть доминирование протестующих и снизить их активность. Это было сделано, и посредством вовлечения в свою деятельность новых активистов, в том числе, из сообщества протестующих. Однако обеспечить доминирование позитивной интерпретации проблемы ввоза московского мусора официальным структурам так и не удалось.

Коалиционность, горизонтальность связей и коммуникаций внутри протестующих стали важными факторами успешности их деятельности. Они позволили вовлечь в информационную кампанию значительное количество активистов, формирующих общественное мнение, вовлекающих новых активистов.

При этом социальные сети выступили эффективным каналом донесения до власти позиции значительной части горожан, выступающих против ввоза московского мусора. Власть не смогла игнорировать их позицию, вырабатывая различные инструменты противодействия протестующим как онлайн, так и офлайн.

Организованная информационная кампания против ввоза московского мусора завершилась, однако ее результат - снижение доверия органам власти и успешный опыт самоорганизации - продолжит оказывать значительное влияние на общественнополитическое пространство региона.

Работа выполнена при финансовой поддержке РФФИ в рамках научноисследовательского проекта № 17-03-00132-ОГН «Коллективные действия граждан по защите и реализации законных прав и интересов в современной России» 


\section{Литература}

[1] Bennett W. L., Segerberg A. The Logic of connective action // Information, Communication and Society. 2012. Vol. 15, № 5. P. 739-768.

[2] Bimber B., Flanagin A. J., Stohl C. Reconceptualizing collective action in the contemporary media environment // Communication Theory. 2005. № 15. P. 367.

[3] Boulianne S. Does internet use affect engagement? A meta-analysis of research // Political Communication. 2009. Vol. 26, № 2. P. 193-211.

[4] Castells M. Networks of Outrage and Hope: Social Movements in the Internet Age. Maiden: Polity. 2012.

[5] Cho J., Shah D. V., McLeod J.M., McLeod D.M., Scholl R.M., Gotlieb M.R. Campaigns, reflection, and deliberation: Advancing an O-S-R-O-R model of communication effects // Communication Theory. 2009. №19. P. 66-88.

[6] Curran J. Mediations of democracy // Mass Media and Society. New York: Oxford University Press, 2005. P. 122-149.

[7] Klandermans B. The Demand and Supply of Participation: Social-Psychological Correlates of Participation in Social Movements // The Blackwell Companion to Social Movements. Oxford: Blackwell. 2004. P. 360-379.

[8] Diani M. Social Movement Networks Virtual and Real // Information, Communication and Society. 2000. Vol. 3, № 3. P. 386-401.

[9] Gerbaudo P. Democracy 2.0 and Other Popular Delusions. London: King's College Londonб, 2013.

[10]Horrigan J., Garrett K., Resnick P. The internet and democratic debate // Pew Internet and American Life Project. 2004. URL: https://www.pewresearch.org/internet/2004/10/27/theinternet-and-democratic-debate/ (дата обращения 20.01.2019).

[11]Jasper J. M., Poulsen J. D. Recruiting Strangers and Friends: Moral Shocks and Social Networks in Animal Rights and Anti-nuclear Protests // Social Problems. 1995. Vol. 42, № 4. P. 493-512.

[12]Lazarsfeld P., Berelson B., Gaudet H. The people's choice: How the voter makes up his mind in a presidential campaign. New York, NY: Duel, Sloan \& Pearce. 1944.

[13] Melucci A. Challenging codes. Collective action in the information age. Cambridge: Cambridge University Press, 1996.

[14]Palfrey J., Gasser U. Born Digital: Understanding the First Generation of Digital Natives. New York: Basic Books, 2008.

[15] Shirky C. Here Comes Everybody: The Power of Organizing Without Organizations. New York: Penguin Press, 2008.

[16] Tufekci Z., Wilson C. Social media and the decision to participate in political protest in Egypt: observations from Tahrir Square // Journal of Communication. 2012. Vol. 62, № 2. P. 363-379.

[17] Tufekfi Z. Capabilities of Movements and Affordances of Digital Media: Paradoxes of Empowerment // dmlcentral blog. January 9, 2014. URL: http://dmlcentral.net/blog/zeyneptufekci/capabilities-movements-and-affordances-digital-media-paradoxes-empowerment (дата обращения 20.01.2019).

[18]Богданова Д. Блоги в системе сетевых коммуникаций. URL: http://www.relga.ru/Environ/WebObjects/tguwww.woa/wa/Main?textid=1093\&level1=main\&level2=articles (дата обращения 20.01.2019).

[19]Володенков С.В. Особенности Интернета как современного пространства политических коммуникаций // Вестник Московского государственного областного университета. 2017. № 4. С. 1-13.

[20]Володенков С.В. Социальные медиа как инструмент современной публичной политики: особенности и перспективы применения // Политическая наука. 2017. № 1. C. 290-305. 
[21]Отрощенко А. Блогу - блогово. Поглотят ли блоги Интернет-CMИ? URL: http://www.lenizdat.ru/a0/ru/pm1/c-1035450-0.html (дата обращения 20.04.2017).

[22] Роменков А.В. Интернет-блог как инструмент политической борьбы // Власть. 2008. № 7. С. 79-82.

[23] Филатова О.Г. Методика и техника социологического исследования: Конспект лекций. СПб: Издательство Михайлова В.А., 2000.

\title{
Social networks sites as a channel of communication with the authorities (on the example of protest movements of the Yaroslavl region)
}

\author{
A. Sokolov, D. Palatnikov
}

\section{Demidov P.G. Yaroslavl State University}

The article is devoted to the analysis of the impact of public campaigns in social networks on the decision-making process by the authorities. The authors consider the main advantages of the Internet, information and communication technologies and social networks. It is stated that it provides opportunities to gain access to alternative sources of information, create conditions for open discussion, involve youth in social and political activity, provide feedback to the activities of government bodies, coordinate collective actions, build a non-hierarchical organizational structure. It is noted that social networks allow the formation of an alternative information space that allows overcoming censorship. The article discusses an example of the influence of a campaign in social networks on the decisions and actions of the authorities in the Yaroslavl region: against storing Moscow garbage in the region. The analysis revealed the intensity of coverage of the problem in social networks, the tools used. The authors conclude that the Internet is becoming an integral part of society, increasing the potential for citizens to influence decisionmaking by the authorities.

Keywords: Internet, social networks, protest, power, communication, collective actions

Reference for citation: Sokolov A., Palatnikov D. Social networks sites as a channel of communication with the authorities (on the example of protest movements of the Yaroslavl region) // The State and Citizens in the Electronic Environment. Vol. 3 (Proceedings of the XXII International Joint Scientific Conference «Internet and Modern Society», IMS-2019, St. Petersburg, June 19-22, 2019). - St. Petersburg: ITMO University, 2019. P. 132 - 143. DOI: $10.17586 / 2541-979 X-2019-3-132-143$

\section{Reference}

[1] Bennett W. L., Segerberg A. The Logic of connective action // Information, Communication \& Society. 2012. № 15(5). pp. 739-768.

[2] Bimber B., Flanagin A. J., Stohl C. Reconceptualizing collective action in the contemporary media environment // Communication Theory. 2005. № 15. P. 367.

[3] Boulianne S. Does internet use affect engagement? A meta-analysis of research // Political Communication. 2009. Vol. 26, № 2. P. 193-211.

[4] Castells M. Networks of Outrage and Hope: Social Movements in the Internet Age // Maiden: Polity. 2012.

[5] Cho J., Shah D. V., McLeod J.M., McLeod D.M., Scholl R.M., Gotlieb M.R. Campaigns, reflection, and deliberation: Advancing an O-S-R-O-R model of communication effects // Communication Theory. 2009. №19. pp. 66-88.

[6] Curran J. Mediations of democracy // Mass Media and Society. New York: Oxford University Press, 2005. P. 122-149. 
[7] Klandermans B. The Demand and Supply of Participation: Social-Psychological Correlates of Participation in Social Movements // The Blackwell Companion to Social Movements. Oxford: Blackwell. 2004. P. 360-379.

[8] Diani M. Social Movement Networks Virtual and Real // Information, Communication and Society. 2000. Vol. 3, № 3. P. 386-401.

[9] Gerbaudo P. Democracy 2.0 and Other Popular Delusions. London: King's College London. 2013.

[10]Horrigan J., Garrett K., Resnick P. The internet and democratic debate // Pew Internet and American Life Project. 2004.

[11] Jasper J. M., Poulsen J. D. Recruiting Strangers and Friends: Moral Shocks and Social Networks in Animal Rights and Anti-nuclear Protests // Social Problems. 1995. Vol. 42, № 4. P. 493-512.

[12] Lazarsfeld P., Berelson B., Gaudet H. The people's choice: How the voter makes up his mind in a presidential campaign. New York, NY: Duel, Sloan \& Pearce. 1944.

[13] Melucci A. Challenging codes. Collective action in the information age. Cambridge: Cambridge University Press, 1996.

[14] Palfrey J., Gasser U. Born Digital: Understanding the First Generation of Digital Natives. New York: Basic Books, 2008.

[15] Shirky C. Here Comes Everybody: The Power of Organizing Without Organizations. New York: Penguin Press, 2008.

[16] Tufekci Z., Wilson C. Social media and the decision to participate in political protest in Egypt: observations from Tahrir Square // Journal of Communication. 2012. Vol. 62, № 2.

[17]Tufekfi Z. Capabilities of Movements and Affordances of Digital Media: Paradoxes of Empowerment // dmlcentral blog. January 9, 2014. URL: http://dmlcentral.net/blog/zeyneptufekci/capabilities-movements-and-affordances-digital-media-paradoxes-empowerment (дата обращения 20.01. 2018).

[18]Bogdanova D. Blogi v sisteme setevykh kommunikatsiy. URL: http://www.relga.ru/Environ/WebObjects/tgu-www. woa/wa/Main?textid=1093\&level1=main\&level2=articles (дата обращения 20.04.2017).

[19] Volodenkov S.V. Osobennosti Interneta kak sovremennogo prostranstva politicheskikh kommunikatsiy // Vestnik Moskovskogo gosudarstvennogo oblastnogo universiteta. 2017. № P. S. 1-13.

[20] Volodenkov S.V. Sotsial'nyye media kak instrument sovremennoy publichnoy politiki: osobennosti i perspektivy primeneniya // Politicheskaya nauka. 2017. № 1. P. 290-305.

[21] Otroshchenko A. Blogu - blogovo. Poglotyat li blogi Internet-SMI? URL: http://www.lenizdat.ru/a0/ru/pm1/c-1035450-0.html (дата обращения 20.04.2017).

[22] Romenkov A.B. Internet-blog kak instrument politicheskoy bor'by // Vlast'. 2008. № 7. P. 79-82.

[23]Filatova O.G. Metodika i tekhnika sotsiologicheskogo issledovaniya: Konspekt lektsiy. SPb.: Izdatel'stvo Mikhaylova V.A., 2000. 